\title{
Polymerase chain reaction-based method for the identification of Leishmania (Viannia) braziliensis and Leishmania (Viannia) guyanensis in mucosal tissues conserved in paraffin
}

\author{
Suzane Ribeiro Prestes ${ }^{[1]}$, Jorge Augusto de Oliveira Guerra ${ }^{[2]}$, \\ Gustavo Adolfo Sierra Romero ${ }^{[3]}$, Laylah Kelre Costa Magalhaes ${ }^{[1]}$, \\ Rosa Amelia Gonçalves Santana ${ }^{[1]}$, Marcel Gonçalves Maciel ${ }^{[1]}$, \\ Ana Custódio ${ }^{[4]}$, Maria das Graças Vale Barbosa ${ }^{[1],[2]}$ \\ and Henrique Silveira ${ }^{[4]}$
}

[1]. Universidade do Estado do Amazonas, Manaus, Amazonas, Brazil. [2]. Fundação de Medicina Tropical Dr. Heitor Vieira Dourado, Manaus, Amazonas, Brazil. [3]. Núcleo de Medicina Tropical, Universidade de Brasília, Brasília, Distrito Federal, Brazil. [4]. Centro de Malária e outras Doenças Tropicais, Instituto de Higiene e Medicina Tropical, Lisboa, Portugal.

\begin{abstract}
Introduction: In the Americas, mucosal leishmaniasis is primarily associated with infection by Leishmania (Viannia) braziliensis. However, Leishmania (Viannia) guyanensis is another important cause of this disease in the Brazilian Amazon. In this study, we aimed at detecting Leishmania deoxyribonucleic acid (DNA) within paraffin-embedded fragments of mucosal tissues, and characterizing the infecting parasite species. Methods: We evaluated samples collected from 114 patients treated at a reference center in the Brazilian Amazon by polymerase chain reaction (PCR) and restriction fragment length polymorphism (RFLP) analyses. Results: Direct examination of biopsy imprints detected parasites in 10 of the 114 samples, while evaluation of hematoxylin and eosin-stained slides detected amastigotes in an additional 17 samples. Meanwhile, 31/114 samples (27.2\%) were positive for Leishmania spp. kinetoplast deoxyribonucleic acid (kDNA) by PCR analysis. Of these, 17 (54.8\%) yielded amplification of the mini-exon PCR target, thereby allowing for PCR-RFLP-based identification. Six of the samples were identified as $L$. (V.) braziliensis, while the remaining 11 were identified as $L$. (V.) guyanensis. Conclusions: The results of this study demonstrate the feasibility of applying molecular techniques for the diagnosis of human parasites within paraffinembedded tissues. Moreover, our findings confirm that $L$. (V.) guyanensis is a relevant causative agent of mucosal leishmaniasis in the Brazilian Amazon.
\end{abstract}

Keywords: PCR. Leishmania braziliensis. Leishmania guyanensis. Mucosal leishmaniasis. Molecular diagnosis.

\section{INTRODUCTION}

Leishmaniasis remains a significant public health problem, occurring in 88 countries around the world. Each year, approximately 0.7-1.2 million people worldwide are affected by tegumentary leishmaniasis, with roughly $187,200-307,800$ of these cases occurring on the American continent ${ }^{(1)}$. Notably, of the 11 Leishmania species known to cause human disease, seven can be found in the Brazilian Amazon ${ }^{(2)(3)(4)(5)}$. While the primary

Corresponding author: Dr. Gustavo Adolfo Sierra Romero. Núcleo de Medicina Tropical/UnB. Campus Universitário Darcy Ribeiro. Caixa Postal 04517, 70904-970 Brasília, Distrito Federal, Brasil.

Phone: 5561 9967-8759

e-mail: gromero@unb.br

Received 24 April 2015

Accepted 19 August 2015 etiological agent of mucosal leishmaniasis (ML) in Brazil is Leishmania (Viannia) braziliensis, Leishmania (Leishmania) amazonensis and Leishmania (Viannia) guyanensis are also associated with mucosal lesions in this country ${ }^{(6)}$.

In a previous study, Marsden(7), in 1986, estimated that $3-5 \%$ of patients with cutaneous leishmaniasis subsequently develop the mucosal form of the disease ${ }^{(7)}$. Because parasites are not easily detected in the lesions of patients with ML, the sensitivity of conventional diagnostic methods ranges between 10 and $45 \%$, rarely surpassing $50 \%^{(7)}$. As such, diagnosis of ML is often based on clinical data associated with a positive result in the leishmanin skin test ${ }^{(8)}$. In a recent meta-analysis, however, Gomes et al. ${ }^{(9)}$ demonstrated that a polymerase chain reaction (PCR)-based method exhibited a sensitivity of $71 \%$ for diagnosis of ML at the genus level ${ }^{(9)}$. In addition, the sensitivity of non-invasive approaches has been studied with some interesting results ${ }^{(10)}$. PCR is a sensitive method that can be used for the detection and characterization of Leishmania 
species $^{(11)(12)}$. Indeed, several reports have considered this approach the method of choice for diagnosing $\mathrm{ML}^{(5)}{ }^{(13)}$. Since Laskay ${ }^{(14)}$ published his study ${ }^{(14)}$, PCR has been utilized for the identification of Leishmania spp. in both paraffin-embedded and nonembedded tissues, emphasizing the significance of this technique amongst available tools for the diagnosis of tegumentary leishmaniasis ${ }^{(15)}$. Diagnosis of the causative agent of ML at the species level is essential, not only for assessing clinical prognoses, but also for the selection of appropriate treatments $^{(16)(17)}$.

In certain instances, patients with leishmaniasis are improperly diagnosed and treated at centers that are inexperienced with Leishmania infections, and it is only after the failure of these treatments that the patients are suspected of having ML. In such cases, the ability to examine paraffin-embedded tissues for the presence of Leishmania spp. could be extremely useful to avoid the repetition of invasive procedures. The combination of conventional PCR coupled with restriction fragment length polymorphism (RFLP) may comprise a more practical approach for diagnosing parasites at the species level than the laborious process of multi-locus enzyme electrophoresis, which depends on the successful isolation of the parasite in culture, an event that is rare in ML patients. Moreover, a method that allows for species-level identification could enhance our knowledge of the parasitic diversity associated with this complex disease, which has traditionally been linked only to $L$. (V.) braziliensis infection.

The purpose of this study was to detect Leishmania deoxyribonucleic acid (DNA) in paraffin-embedded biopsies of mucosal tissue harvested from the upper airways of patients that were followed-up at a reference center for the treatment of leishmaniasis in the Brazilian Amazon. Furthermore, we aimed at achieving species-level identification of the parasite(s) associated with mucosal impairment via PCR coupled with RFLP.

\section{METHODS}

\section{Sampling}

This study was conducted at the Fundação de Medicina Tropical-Heitor Vieira Dourado (FMT-HVD), in Manaus, State of Amazonas, Brazil. Since 1990, FMT-HVD has functioned as a tertiary health unit that assists patients bearing lesions suspected to result from leishmaniasis. For such patients, routine procedures include histopathological examination of biopsies collected from upper airway tissues, which are fixed in $10 \%$ buffered formaldehyde, and subsequently embedded in paraffin and archived in the Pathology Unit of FMT-HVD.

Sampling was defined by convenience and included biopsies of the upper airway mucosa of patients presenting lesions suspected to be ML. All biopsies were subjected to histopathological analysis between 1992 and 2008. Samples were identified from the pathology service logbook, which contains a record of the dates of clinical procedures and the results of histopathological examinations. The 114 biopsy tissues examined in this study were chosen based on the presence of at least nonspecific inflammatory infiltrates, independent of the presence of Leishmania amastigotes, as determined by histopathological examination. In contrast, inclusion in the study was not dependent on parameters such as the extent of disease progression, previous exposure to treatment, or patient gender and age. Of the 114 samples analyzed, 91 were obtained from male patients, and 23 were obtained from female patients. A total of 59 samples were collected between 1992 and 2000, while the remaining 55 samples were collected between 2001 and 2008.

\section{Histopathology}

For histopathological diagnosis, hematoxylin and eosin (HE)-stained slides were examined by light microscopy to detect inflammatory infiltrates and/or the amastigote form of the parasite.

\section{Definition of cases of suspected mucosal leishmaniasis}

Cases of suspected mucosal leishmaniasis were clinically defined by the presence of damage to the mucosal lining of the upper airway resulting in ulcers, in vegetative or necrotic lesions of the cartilaginous septum (with or without perforation), nasal turbinate, soft and hard palate, uvula, pharynx, or larynx, or deforming of the nasal pyramid ${ }^{(7)}$. The team that conducted the present study was comprised of researchers that have been employed at FMT-HVD since at least 1990, and have experience with both ML and the use of the above-mentioned parameters for evaluating biopsies of the upper airway mucosa. Patients' data, including the date of biopsy collection, age, gender, and the presence/absence of parasites upon conventional histopathological examination, were obtained retrospectively from medical records maintained by the institution.

\section{DNA extraction from tissues embedded in paraffin}

Twelve $20-\mu \mathrm{m}$ sections were obtained from each block of paraffin-embedded tissue and stored in $1.5 \mathrm{~mL}$ microtubes at room temperature until further use. Paraffin removal was performed by incubation with xylol for $5 \mathrm{~min}$ at room temperature, followed by centrifugation at $14,000 \mathrm{rpm}$ for $5 \mathrm{~min}$ at room temperature. The resulting pellet were washed twice with absolute ethanol, collected by centrifugation at $14,000 \mathrm{rpm}$ for $5 \mathrm{~min}$ at room temperature, and air dried for 30 min at $37^{\circ} \mathrm{C}$. DNA was then extracted using a DNeasy Blood \& Tissue Kit (Qiagen $\AA$, Venlo, Netherlands), according to the manufacturer's instructions.

\section{PCR amplification of the Leishmania kDNA target sequence}

To detect Leishmania spp., PCR was utilized to amplify a 116 base pair (bp) constant region from the kinetoplast deoxyribonucleic acid (kDNA) mini-circle (henceforward referred to as PCR $13 \mathrm{a} / 13 \mathrm{~b})$, as described previously ${ }^{(18)}$. DNA harvested from cultures of $L$. (V.) guyanensis (MHOM/BR/1975/ M4147) and L. (V.) braziliensis (MHOM/BR/1975/M2903) were used as positive controls. To rule out false-negatives resulting from DNA degradation or to the presence of inhibitors, samples in which the PCR $13 \mathrm{a} / 13 \mathrm{~b}$ product was not detected were 
subjected to a second PCR reaction using primers designed to target a specific $147 \mathrm{bp}$ region of the human actin gene (ACTB ENSG00000075624, Ensemble).

\section{PCR-RFLP of the mini-exon gene}

For identification of parasite species, DNA samples that were positive for the PCR 13a/13b fragment were subjected to a second PCR analysis accompanied by enzymatic digestion. Amplification reactions were conducted using the following oligonucleotide primers, as described by Marfurt et al. ${ }^{(19)}$ : Fme (5'-TAT TGG TAT GCG AAA CTT CCG-3') and Rme (5'-ACA GAAACT GAT ACT TAT ATA GCG-3'). The Leishmania spp. present in each sample were subsequently identified by analyzing the fragments generated via restriction enzyme digestion with HaeIII and NcoI for $2.5 \mathrm{~h}$ at $37^{\circ} \mathrm{C}$. Specifically, while HaeIII cleaves the product amplified from $L$. (V.) braziliensis into 118 and 108bp fragments, NcoI cleaves the $L$. (V.) guyanensis amplification product into 173 and 53bp fragments ${ }^{(19)}$. Digestion products were separated by $3 \%$ agarose gel electrophoresis and visualized by ethidium bromide staining.

\section{Ethical considerations}

The present study was conducted following the principles of the Helsinki Declaration and the resolution of National Health Council, which regulates research that involves humans in Brazil. This study has been approved by the FMT-HVD Ethics in Research Committee (protocol number 1674/06).

\section{RESULTS}

Direct examination detected parasites in 10 of the $114(8.8 \%)$ samples tested, while histopathological examination detected amastigotes in an additional $17(17 / 114 ; 14.9 \%)$ samples. Furthermore, $31(31 / 114 ; 27.2 \%)$ samples were positive for the Leishmania spp. kDNA target (PCR 13a/13b) as shown in Figure 1. Of these, only 17 (54.8\%) yielded amplification of the mini-exon PCR product and could therefore be analyzed by PCR-RFLP. While 6 of the samples were identified as $L$. $(V$.) braziliensis, the other 11 were confirmed as $L$. $(V$.) guyanensis. Notably, only partial digestion of the DNA product resulting from the PCR mini-exon assay was observed using the conventional protocol. As a result, it was necessary to increase the digestion time to $3 \mathrm{~h}$ to achieve optimal digestion (Figure 2). Lastly, the human actin gene was successfully amplified in each of the 83 samples that were PCR 13a/13b-negative.

\section{DISCUSSION}

Given their dependence on parasite visualization within affected tissues or on parasite isolation in culture, the use of conventional tools to diagnose Leishmania spp. as the causative agent of damage to the upper airway mucosa remains a major challenge ${ }^{(7)}(20)$. Moreover, because these techniques are associated with low levels of accuracy, the development of methods, such as PCR-based diagnostic methods, that yield higher levels of sensitivity and specificity is necessary ${ }^{(13)}{ }^{(21)}$.

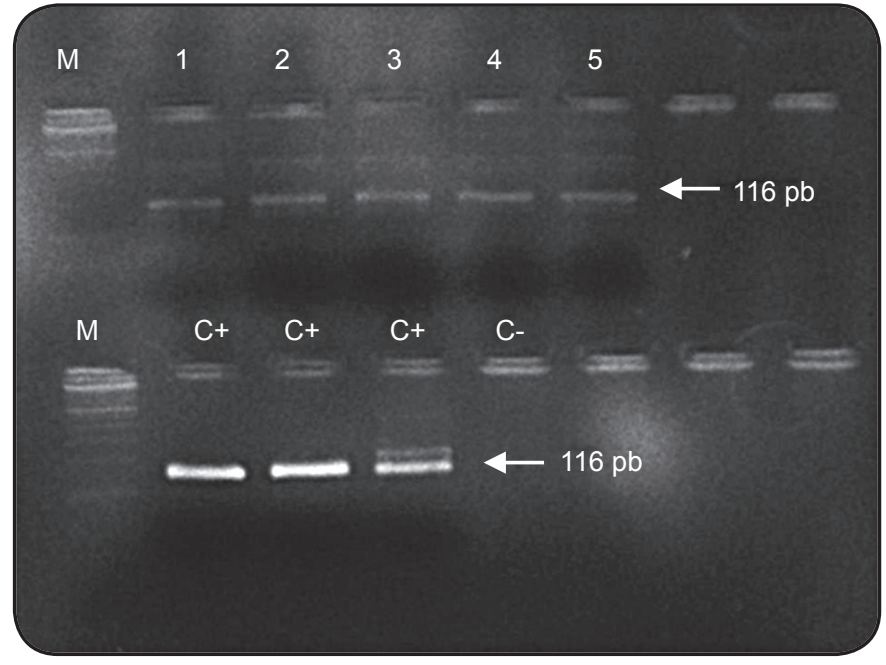

FIGURE 1 - Electrophoretic analysis of PCR 13a/13b fragments. Samples were separated by $2 \%$ agarose gel electrophoresis. Five samples were positive for Leishmania spp. [116 base pair (bp amplicon]. Lanes 1, 2, 3, 4 and 5: M: 100bp molecular marker; C+: positive control; C-: negative control; The positive controls were as follows: Leishmania (Viannia) braziliensis (MHOM/ BR/1975/M2903), Leishmania (Viannia) guyanensis (MHOM/ BR/1975/M4147), and Leishmania (Leishmania) amazonensis (IFLA/BR/1967/PH8). PCR: polymerase chain reaction.

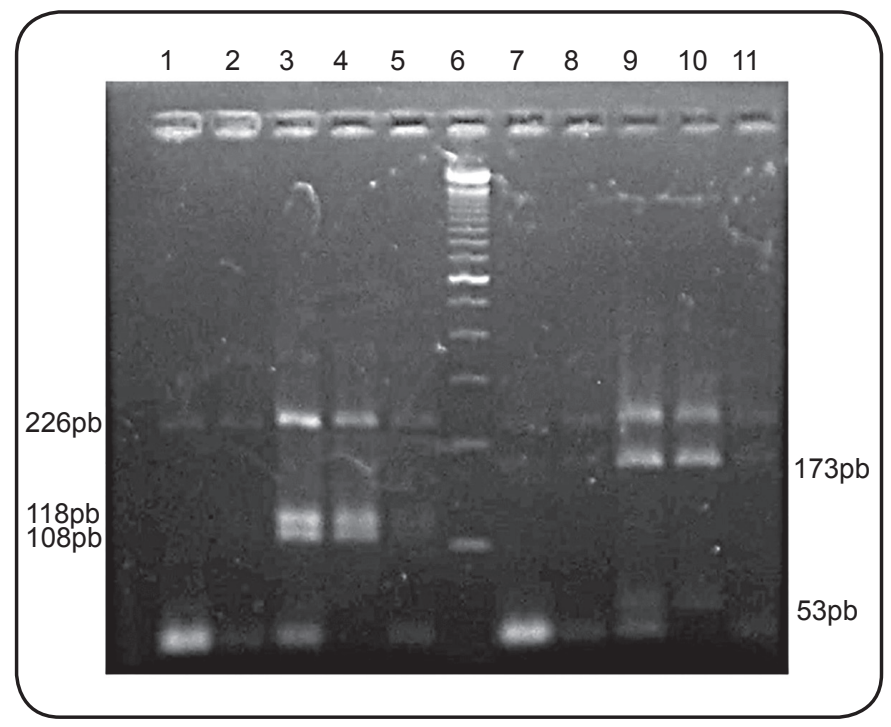

FIGURE 2 - Enzymatic digestion analysis of DNA products generated by mini-exon PCR. PCR products were restriction digested with HaeIII and NcoI, and separated by $3 \%$ agarose gel electrophoresis. Lanes 1, 2, 3, and 5 correspond to patient DNA samples digested with HaeIII, while lanes 7, 8, 9, and 11 contain patient DNA samples digested with NcoI. Lanes 4 and 10 contain the positive control [Leishmania (Viannia) guyanensis (MHOM/BR/1975/M4147)] DNA digested with HaeIII and NcoI, respectively. Lane 6 contains the 100 base pair (bp) DNA ladder. DNA: deoxyribonucleic acid; PCR: polymerase chain reaction. 
In this study, we successfully detected genus-specific DNA fragments in a large number of mucosal samples collected from the upper airway of Brazilian patients suspected of leishmaniasis. Notably, our results indicate that the methodology utilized in this study would have provided confirmatory results for a third of these suspected ML patients.

Given the lack of specificity of the clinical parameters used for inclusion in this study, we expected that the majority of the patients evaluated would by negative for parasites upon PCR analysis. Unfortunately, due to a lack of systematic collection of additional relevant data during the period in which these patients were being treated, it was not possible to determine a definitive diagnosis for those patients that tested negative for Leishmania spp. Nevertheless, our study demonstrates the need for further exploration of the role of $L$. (V.) guyanensis in ML etiology, a disease that has traditionally been linked to $L$. (V.) braziliensis infection ${ }^{(7)}$. Indeed, there is a scarcity of information regarding the role of $L$. (V.) guyanensis in ML. While a previous study performed at FMT-HVD in the 1990s demonstrated the predominance of $L$. (V.) guyanensis among cases of cutaneous leishmaniasis ${ }^{(22)}$, the relative frequency of the mucosal impairment caused by this species remains unknown. Furthermore, consistent with recent findings in Brazil ${ }^{(5)}$, cases of ML caused by $L$. (V.) guyanensis and $L$. (V.) panamensis were recently described in Colombia ${ }^{(23)(24)}$. In the present study, PCRRFLP analysis detected a higher number of cases of infection by $L$. (V.) guyanensis than by $L$. (V.) braziliensis. However, this result should be assessed with caution, as skin ulcers caused by $L .(V)$ guyanensis appear to be associated with higher parasite burdens than ulcers caused by $L$.(V.) braziliensis ${ }^{(17)}$. Regardless, these findings highlight the feasibility of using molecular techniques both for analyzing paraffin-conserved biological material and for diagnosing ML. Furthermore, they demonstrate that PCR-RFLP comprises a method that can be utilized to achieve species-specific diagnoses. The efficacy of methods for the extraction of optimal concentrations of DNA with high levels of purity and integrity from paraffin-embedded tissues is essential for the molecular diagnostic approach utilized in this study. Nonetheless, the processes of formaldehyde fixation and inclusion into paraffin are limiting steps for the molecular detection of parasites ${ }^{(14)(15)(25)(26)}$.

In the present study, human DNA was amplified from all biopsy-extracted DNA samples. However, the relative abundance of this target, which was used as control for DNA extraction, does not necessarily mean that the parasite DNA was not degraded during fixation and conservation ${ }^{(27)}$. The length of time during which samples are maintained in paraffin blocks is an important factor for DNA amplification, as previous research indicates that there is a negative correlation between the duration of storage and PCR success ${ }^{(25)}$. In the present study, while storage duration was not a limiting factor for the amplification of the human actin gene, it could have had deleterious effects on the detection of Leishmania spp. and on the identification of parasite species. Indeed, when compared to samples that had been stored for shorter periods, a small number of the older samples were positive in the PCR assay and yielded faint bands upon electrophoretic analysis.
The low percentage of Leishmania-positive samples in this study might have been due, at least in part, to degradation of the parasite DNA, as fixation promotes folding of nuclear proteins and the degradation of DNA molecules ${ }^{(28)}$. In addition, parasite numbers within mucosal lesions are often low $^{(29)}$. Given that the efficiency of DNA amplification decreases as the target DNA fragment size increases, targeting of the PCR 13a/13b fragment, which is both abundant ${ }^{(30)}$ and small, may provide a plausible explanation for the positive results achieved with this test, compared to that of mini-exon PCR-RFLP analysis ${ }^{(26)(31)}$. In summary, the present study demonstrates the efficacy of molecular techniques for diagnosis of ML using paraffin-embedded tissues. Our data also confirm that $L$. (V.) guyanensis comprises a relevant etiological agent of ML in the Brazilian Amazon.

\section{CONFLICT OF INTEREST}

The authors declare that there is no conflict of interest.

\section{FINANCIAL SUPPORT}

The author (HS) received a visiting fellowship from the Science without Borders Program [Coordenação de Aperfeiçoamento de Pessoal de Nivel Superior (CAPES/Conselho Nacional de Desenvolvimento Cientifico e Tecnológico (CNPq)], and the author (GASR) received a visiting fellowship from the Strategic Program for Science, Technology \& Innovation [Programa Estratégico de Ciência, Tecnologia e Inovação (PECTI-SAÚDE) of Fundação de Amparo à Pesquisa do Estado do Amazonas (FAPEAM). This study was partially funded by the Fundação de Medicina Tropical Dr. Heitor Vieira Dourado, FAPEAM/CNPq/ Programa Primeiros Projetos - edital 010/2011 and Ministério da Ciência e Tecnologia/CNPq - grant number 014/2011.

\section{REFERENCES}

1. Alvar J, Vélez ID, Bern C, Herrero M, Desjeux P, Cano J, et al. Leishmaniasis worldwide and global estimates of its incidence. PLoS One 2012; 7:e35671.

2. Guerra JAO, Talhari S, Paes MG, Garrido M, Talhari JM. Aspectos diagnósticos da leishmaniose tegumentar americana em militares simultaneamente expostos à infecção na Amazônia. Rev Soc Bras Med Trop 2003; 36:587-590.

3. SilveiraFT, Lainson R, CorbettCEP.Clinicalandimmunopathological spectrum of American cutaneous leishmaniasis with special reference to the disease in Amazonian Brazil - A Review. Mem Inst Oswaldo Cruz 2004; 99:239-251.

4. Guerra JAO, Maciel MG, Guerra MV, Talhari AC, Prestes SR, Fernandes MA, et al. Tegumentary leishmaniasis in the State of Amazonas: what have we learned and what do we need? Rev Soc Bras Med Trop 2015; 48 (supl I):12-19.

5. Guerra JAO, Prestes SR, Silveira H, Coelho LIARC, Gama P, Moura A, et al. Mucosal leishmaniasis caused by Leishmania (Viannia) braziliensis and Leishmania (Viannia) guyanensis in the Brazilian Amazon. PloS Negl Trop Dis 2011; 5:e980.

6. Naiff MF, Cupolillo E, Naiff RD, Momen H, Barret TV, Grimaldi Jr G. Leishmnaiose tegumentar americana na Amazônia: distribuição 
geográfica dos agentes etiológicos na região. Rev Soc Bras Med Trop 1999; 32:243.

7. Marsden PD. Mucosal leishmaniasis ("Espundia" Escomel, 1911) Trans R Soc Trop Med Hyg 1986; 80:859-876.

8. Reed SG. Diagnosis of leishmaniasis. Clin Dermatol 1996; 14: 471-478.

9. Gomes CM, Mazin SC, Santos ER, Cesetti MV, Bächtold GAB, Cordeiro JHF, et al. Accuracy of mucocutaneous leishmaniasis diagnosis using polymerase chain reaction: systematic literature review and meta-analysis. Mem Inst Oswaldo Cruz 2015; 110: 157-165.

10. Gomes CM, de Paula NA, Cesetti MV, Roselino AM, Sampaio RN. Mucocutaneous leishmaniasis: accuracy and molecular validation of noninvasive procedures in a $L$. $(V$.) braziliensis-endemic area. Diagn Microbiol Infect Dis 2014; 79:413-418.

11. Aviles H, Belli A, Armijos R, Monroy FP, Harris E. PCR detection and identificacion of Leishmania parasite in clinical specimens in Ecuador: a comparation with classical diagnostic methods. J Parasitol 1999; 85:181-187.

12. Belli A, Rodrigues B, Aviles H, Harris E. Simplified polymerase chain reaction detection of New World Leishmania in clinical specimens of cutaneous leishmaniasis. Am J Trop Med Hyg 1998; 58:102-109.

13. Oliveira JG, Novaes OF, Oliveira CI, Cruz JA, Campos FL, Rocjha A, et al. Polymerase chain reaction (PCR) is highly sensitive for diagnosis of mucosal leishmaniasis. Acta Trop 2005; 94:55-59.

14. Laskay T, Miko LT, Solbach W, Röllinghoff M, Frommel D. Detection of cutaneous Leishmania infection in paraffin-embedded skin biopsies using the polymerase chain reaction. Trans R Soc Trop Med Hyg 1995; 89:273-275.

15. Mimori T, Sasaki J, Nakata M, Gomez EA, Uezato H, Nonaka S, et al. Rapid identification of Leishmania species from formalinfixed biopsy samples by polymorphism-specific polymerase chain reaction. Gene 1998; 210:179-186.

16. Romero GA, Guerra MVF, Paes MG C, Macêdo VO. Comparison of cutaneous leishmaniasis due to Leishmania (Viannia) braziliensis and L. (V.) guyanensis in Brazil: therapeutic response to meglumine antimoniate. Am J Trop Med Hyg 2001a; 65:456-465.

17. Romero GA, Guerra MVF, Paes MG, Macêdo VO. Comparison of cutaneous leishmaniasis due to Leishmania (Viannia) braziliensis and $L$. (V.) guyanensis in Brazil: clinical findings and diagnostic approach. Clin Infect Dis 2001; 32:1304-1312.

18. Reale S, Maxia L, Vitale F, Glorioso NS, Caracappa S, Vesco G. Detection of Leishmania infantum in dogs by PCR with lymph node aspirates and blood. J Clin Microbiol 1999; 37:2931-2935.

19. Marfurt J, Nasereddin A, Niederwieser I, Jaffe CL, Beck HP, Felger I. Identification and differentiation of Leishmania species in clinical samples by PCR amplification of the miniexon sequence and subsequent restriction fragment length polymorphism analysis. J Clin Microbiol 2003; 41:3147-3153.

20. Disch J, Pedras MJ, Orsini M, Pirmez C, Oliveira MC, Castro M, et al. Leishmania (Viannia) subgenus kDNA amplification for the diagnosis of mucosal leishmaniasis. Diag Microbiol Infect Dis 2005; 51:185-190.

21. Bracho CO, Porras de Quintana L, Arenas MS, Parras MR. Polymerase chain reaction with two molecular targets in mucosal leishmaniasis' diagnosis: a validation study. Mem Inst Oswaldo Cruz 2007; 102:549-554.

22. Romero GA, Ishikawa E, Cupolillo E, Toaldo CB, Guerra MV, Paes MG, et al. The rarity of infection with Leishmania (Viannia) braziliensis among patients from the Manaus region of Amazonas state, Brazil, who have cutaneous leishmaniasis. Ann Trop Med Parasitol 2002; 96:131-136.

23. Santrich C, Segura I, Arias AL, Saravia NG. Mucosal disease caused by Leishmania braziliensis guyanensis. Am J Trop Med Hyg 1990; 42:51-55.

24. Osorio LE, Castillo CM, Ochoa MT. Mucosal leishmaniasis due to Leishmania (Viannia) panamensis in Colombia: clinical characteristics. Am J Trop Med Hyg 1998; 59:49-52.

25. Libório TN, Etges A, Neves AC, Mesquita RA, Nunes FD. Evaluation of the genomic DNA extracted from formalin-fixed, paraffin-embedded oral samples archived for the past 40 years. J Bras Patol Med Lab 2005; 41:405-410.

26. Lehmann U, Kreipe H. Real-time PCR analysis of DNA and RNA extracted from formalin-fixed and paraffin-embedded biopsies. Methods 2001; 25:409-418.

27. Bielawski K, Zaczek A, Lisowska U, Dybikowska A, Kowalska A, Falkiewicz B. The suitability of DNA extracted from formalinfixed, paraffin-embedded tissues for double differential polymerase chain reaction analysis. Int J Mol Med 2001; 8:573-578.

28. Isola J, DeVries S, Chu L, Ghazvini S, Waldman F. Analysis of changes in DNA sequence copy number by comparative genomic hybridization in archival paraffin-embedded tumor samples. Am J Pathol 1994; 145:1301-1308.

29. Andresen K, Gaafar A, El-Hassan AM, Ismail A, Dafalla M, Theander TG, et al. Evaluation of the polymerase chain reaction in the diagnosis of cutaneous leishmaniasis due to Leishmania major: a comparison with direct microscopy of smears and section from lesions. Trans R Soc Trop Med Hyg 1996; 90:133-135.

30. Rodgers MR, Popper SJ, Wirth DF. Amplification of kinetoplast DNA as a tool in the detection and diagnosis of Leishmania. Exp Parasitol 1990; 71:267-275.

31. Liu J, Johnson RM, Traweek ST. Rearrangement of the BCL-2 gene in follicular lymphoma. Detection by PCR in both fresh and fixed tissue samples. Diagn Mol Pathol 1993; 2:241-247. 